\title{
COMPORTAMENTO DE GENÓTIPOS DE FEIJOEIRO AO ATAQUE DE BEMISIA TABACI (GENN.) BIÓTIPO B (HEMIPTERA: ALEYRODIDAE)
}

\section{F.G. Jesus ${ }^{1}$, B.C. Martins ${ }^{2}$, F.S. Rocha ${ }^{2}$, A.L. Boiça Junior ${ }^{3}$, S.A.M. Carbonel ${ }^{4}$, A.F. Chiorato ${ }^{4}$}

${ }^{1}$ Instituto Federal Goiano, Laboratório de Entomologia Agrícola, Rod. Prof. Geraldo da Silva Nascimento, km 2,5, CEP 75790-000, Urutaí, GO, Brasil. E-mail. fgjagronomia@zipmail.com.br

\author{
RESUMO
}

Avaliou-se o comportamento de genótipos de feijoeiro sob infestação de Bemisia tabaci (Genn.) biótipo B em condições de campo, nas épocas de cultivo "da seca" e "das águas". Utilizaram-se os genótipos IAC-Tybatã, IAC-Una, FT-Nobre, Pérola, LP 98-122, LP 02-130, LP 01-38, LP 9979, BRS-Pontal, BRS-Requinte, BRS-Triunfo, BRS-Grafite, CV-48 e Z-28. Adotou-se o delineamento de blocos casualizados com 14 tratamentos e três repetições. As avaliações foram realizadas semanalmente, contando-se o número de ovos e de ninfas de B. tabaci biótipo B em dez folíolos por parcela. Na safra "da seca" os genótipos menos ovipositados por B. tabaci biótipo B foram IAC-Una e LP 02-130 e os mais ovipositados foram os genótipos Z-28 e Pérola. As menores presenças de ninfas de mosca-branca foram observadas em LP 98-122 e FT-Nobre e as maiores em LP 01-38, Pérola e Z-28. Para a safra "das águas" os genótipos não diferiram entre si em relação ao ataque de $B$. tabaci biótipo B. Os fatores da produção apresentaram diferença estatística somente na safra das secas.

PALAVRAS-CHAVE: Phaseolus vulgaris, mosca-branca, resistência de plantas a insetos.

\section{ABSTRACT}

BEHAVIOR OF BEAN GENOTYPES TO ATTACK BY BEMISIA TABACI (GENN.) BIOTYPE B (HEMIPTERA: ALEYRODIDAE). Bean genotypes were evaluated under the infestation of Bemisia tabaci (Genn.) biotype B under field conditions in the dry and rainy season. The genotypes used were IAC-Tybatã, IAC-Una, FT-Nobre, Pérola, LP 98-122, LP 02-130, LP 01-38, LP 9979, BRSPontal, BRS-Requinte, BRS-Triunfo, BRS-Grafite, CV-48 and Z-28. The experiment was arranged in randomized blocks with 14 treatments and 3 replications. The evaluations were made on a weekly basis by counting $B$. tabaci biotype B eggs and nymphs on 10 leaflets per plot. In the dry season the least oviposited genotypes by B. tabaci biotype B were IAC-Una and LP 02-130, while the most oviposited were Z-28 and Pérola. The least presence of nymphs of whitefly was observed on LP 98-122 and FT-Nobre, and the most on LP 01-38, Perola and Z-28. For the rainy season the genotypes did not differ in relation to the attack of $B$. tabaci biotype B. The yield factors presented a statistical difference only in the dry season.

KEY WORDS: Phaseolus vulgaris, whitefly, host plant resistance.

\section{INTRODUÇÃO}

OBrasil destaca-se na produção mundial de feijão (Phaseolus vulgaris L.) e também por ser considerado o maior consumidor, encontrando nessa leguminosa sua principal fonte protéica vegetal. Ofeijoeiroéuma das principais culturas plantadas na entressafra em sistemas irrigados, na região central e sudeste do Brasil (BARBOSA FilHo et al., 2001).

Embora o Brasil seja o maior produtor e o maior consumidor mundial de feijão, a produtividade na- cional é considerada baixa, em torno de $700 \mathrm{~kg}$. ha ${ }^{-1}$, e está centrada em pequenos produtores. Segundo MagalHães; CARVALHo (1998) esses valores podem ser atribuídos, entre outros fatores, a estresses ambientais e ao baixo nível tecnológico empregado pelo produtor brasileiro.

A cultura do feijoeiro é de relevante importância no estado de Goiás. Ocupa, anualmente, uma área aproximada de 130.100 hectares, com produção em torno de 446.600 toneladas e rendimento médio por safra ao redor de 1.895 kg.ha-1 (VIEIRA et al., 2006).

${ }^{2}$ Universidades Estadual de Goiás, Unidade Universitária de Ipameri, Ipameri, GO, Brasil.

${ }^{3}$ Universidade Estadual P aulista, Departamento de Fitossanidade, Jaboticabal, SP, Brasil.

${ }^{4}$ Instituto Agronômico, Centro de Análises e Pesquisa Tecnológica do Agronegócio dos Grãos e Fibras, Campinas, SP, Brasil. 
Vários fatores influenciam a produtividade desta cultura e, entre estes podem ser citadas as pragas, merecendo destaque a mosca branca Bemisia tabaci biótipo B, que prejudica o feijoeiro pela transmissão do vírus do mosaico-dourado e, dependendo da época do ano, e das plantas hospedeiras as perdas podem ser totais (Silva et al., 1993).

Entre as causas da alta incidência da moscabranca estão a expansão da área de plantio da soja, uma das plantas hospedeiras preferenciais do inseto, a ampliação da época de semeadura e os cultivos sucessivos e escalonados do feijoeiro com o uso de pivô-central (VIEIRA et al., 1998).

Ocontrole demoscas-brancas tem sido feito quase que exclusivamente por inseticidas e por tratos culturais (PRABHAKER et al., 1985). Em razão de problemas causados pelos inseticidas no agroecossistema, métodos alternativos de controle vêm sendo estudados. Entre esses métodos, pode-se citar a resistência de plantas a insetos (LARA, 1991).

O estudo de resistência varietal a $B$. tabaci biótipo $B$ é uma área que pode e deve ser explorada com o intuito de reduzir os danos causados por esse inseto (MCAUSLANE, 1996), apresentando grande potencial comoestratégia demanejoemum programaintegrado.

Portanto, o objetivo do trabalho foi discriminar genótipos de feijoeiro, quanto ao ataque à moscabranca, observando parâmetros referentes à produtividade em duas épocas de cultivo.

\section{MATERIAL E MÉTODOS}

O experimento da safra "da seca" foi instalado e conduzido no período de abril de 2007 a junho de 2007, e da safra "das águas" no período de dezembro de 2007 a fevereiro de 2008, sendo o primeiro conduzido no Município de Catalão, GO e o segundo na Universidade Estadual de Goiás na Unidade Universitária de Ipameri, GO.

O delineamento experimental adotado foi o de blocos casualizados com 14 tratamentos correspondentes aos genótipos IAC-Tybatã, IAC-Una, FT-Nobre, Pérola, LP 98-122, LP 02-130, LP 01-38, LP 9979, BRS-Pontal, BRS-Requinte, BRS-Triunfo, BRS-Grafite, CV-48 e Z-28 e três repetições.

Cada parcela foi constituída de quatro linhas de $4 \mathrm{~m}$ de comprimento, totalizando $8 \mathrm{~m}^{2}$ de área total e $4 \mathrm{~m}^{2}$ de área útil, totalizando uma área experimental de $336 \mathrm{~m}^{2}$. O espaçamento de plantio da cultura foi de $0,50 \mathrm{~m}$ na entre linha, com densidade de 12 plantas por metro linear. $\mathrm{Na}$ adubação de plantio foram utilizados $430 \mathrm{~kg} \cdot \mathrm{ha}^{-1}$ da fórmula 04-14-08 e em cobertura $180 \mathrm{~kg} \cdot \mathrm{ha}^{-1}$ de sulfato de amônia ao redor dos 20 dias após a emergência.

A partir de 20 dias após a emergência do feijoeiro as amostragens de incidência de mosca-branca foram realizadas semanalmente, contando-se o número de ovos e de ninfas de $B$. tabaci biótipo B em dez folíolos por parcela, retirados da parte mediana da planta, que segundo RossetTo et al. (1977) constitui a região de maior preferência pela praga, até aos 42 dias após a emergência. A avaliação da porcentagem de plantas com sintomas de mosaico-dourado foi realizada aos 30 e 50 dias após a emergência das plantas.

Quando as vagens atingiram a maturidade fisiológica (com, aproximadamente, 110 dias após a semeadura), foi feita a colheita manual das duas linhas centrais, da área útil de cada parcela. No momento da colheita foi contada o número de plantas da área útil de cada parcela e, destas foram coletadas dez plantas, das quais anotaram-se o número de vagens, a massa total de grãos, a massa de 100 grãos e o número de grãos porvagem. Coma trilhagem das plantas somada à massa dos grãos destas dez colhidas, foi calculado o rendimento de grãos por hectare em cada tratamento.

Os dados coletados foram submetidos à análise de variância através dotesteFeas médiasforam comparadas pelo teste de Tukey ao nível de 5\% de significância.

\section{RESULTADOS E DISCUSSÃO}

Na Tabela1, encontram-seos dados donúmero de ovos por dez folíolos, nos genótipos estudados, onde constatou-se que ocorreram diferenças estatísticas significativas somente aos 21 dias após a emergência das plantas (DAE). Para a avaliação realizada aos 21 DAE, observa-se menores oviposições em LP 02-130, LP 9979, LP 98-122, Pérola, BRS-Grafite, CV-48 e BRS-Pontal $(2,0 ; 3,7 ; 4,3 ; 5,3 ; 6,0 ; 6 ; 0$ e 7,3 ovos respectivamente), já a maior oviposição foi observada no genótipo Z-28 (46,7 ovos).

ORIANI et al. (2005) estudando a oviposição de $B$. tabaci biótipo Bemgenótipos de feijoeiro portadores de arcelina em condições de telado, observaram menores taxas de oviposições naqueles portadores deste gene, caracterizandoresistência dotiponão-preferência para oviposição. Segundo os mesmos autores, o cultivar Bolinha foi suscetível a praga e que esta preferência pode estar relacionada ao grande número de tricomas aciculares longos presentes neste material.

Os dados do número médio de ninfas de moscabranca por dez folíolos aos 14, 21, 28, 35 e 42 (DAE), encontram-se na Tabela 2.

Verificam-se diferenças significativas entre os genótipos somente nas avaliações de 21 e 28 (DAE). Aos 21 (DAE) com menores infestações, destacaramse os genótipos LP 98122 e CV-48 (35,3 e 44,0 ninfas) respectivamente, o que sugere que tais genótipos apresentam resistência do tipo não-preferência para oviposição e/ou antibiose. Já o genótipo LP 01-38 (252,2 ninfas) apresentou-se como o mais infestado por ninfas da praga nos folíolos avaliados. 
Tabela 1 - Número médio de ovos de Bemisia tabaci biótipo B em dez folíolos, obtidos em 14 genótipos de feijoeiro, em cinco amostragens na safra "da seca”. Catalão, GO, 2007.

\begin{tabular}{|c|c|c|c|c|c|c|}
\hline \multirow{2}{*}{ Genótipos $^{1}$} & \multicolumn{5}{|c|}{ Dias após a emergência das plantas } & \multirow{2}{*}{ Média } \\
\hline & 14 dias & 21 dias & 28 dias & 35 dias & 42 dias & \\
\hline 1-IAC-Tybatã & 42,0 & $11,0 \mathrm{ab}$ & 16,0 & 4,0 & 12,0 & 17,0 \\
\hline 2- IAC-Ũna & 5,3 & $16,0 \mathrm{ab}$ & 15,0 & 8,0 & 5,0 & 9,86 \\
\hline 3- FT-Nobre & 72,7 & $12,0 \mathrm{ab}$ & 10,3 & 3,3 & 6,7 & 21,0 \\
\hline 4- Pérola & 117,7 & $5,3 \mathrm{~b}$ & 11,3 & 8,0 & 12,0 & 30,9 \\
\hline 5- LP 98-122 & 24,7 & $4,3 \mathrm{~b}$ & 16,0 & 1,0 & 12,0 & 11,6 \\
\hline 6- LP 02-130 & 28,0 & $2,0 \mathrm{~b}$ & 12,0 & 1,7 & 4,7 & 9,7 \\
\hline 7- LP 01-38 & 69,7 & $12,0 \mathrm{ab}$ & 6,3 & 2,3 & 6,0 & 19,2 \\
\hline 8- LP 99-79 & 117,0 & $3,7 \mathrm{~b}$ & 13,3 & 4,0 & 15,3 & 30,6 \\
\hline 9- BRS-Pontal & 65,3 & $7,3 \mathrm{~b}$ & 9,0 & 2,3 & 4,0 & 17,6 \\
\hline 10- BRS-Requinte & 109,0 & $14,3 \mathrm{ab}$ & 5,3 & 9,3 & 9,3 & 29,4 \\
\hline 11- BRS-Triunfo & 63,0 & $18,0 \mathrm{ab}$ & 7,7 & 6,7 & 3,0 & 19,7 \\
\hline 12- BRS-Grafite & 24,3 & $6,0 \mathrm{~b}$ & 14,7 & 14,7 & 1,3 & 12,2 \\
\hline 13- CV-48 & 45,3 & $6,0 \mathrm{~b}$ & 18,7 & 4,0 & 5,3 & 15,9 \\
\hline 14- Z-28 & 102,0 & $46,7 \mathrm{a}$ & 19,3 & 10,7 & 14,7 & 30,7 \\
\hline F (Tratamentos) & $0,87^{\mathrm{NS}}$ & $3,19^{* *}$ & $0,84^{\mathrm{NS}}$ & $0,99^{\mathrm{NS}}$ & $1,85^{\mathrm{NS}}$ & $1,63^{\mathrm{NS}}$ \\
\hline C. V. $(\%)$ & 47,57 & 39,18 & 36,43 & 58,19 & 37,16 & 33,94 \\
\hline
\end{tabular}

${ }^{1}$ Para analise os dados foram transformados em $(x+0,50)^{1 / 2}$

Tabela 2 - Número médio de ninfas de Bemisia tabaci biótipo B em dez folíolos, obtidos em 14 genótipos de feijoeiro, em cinco amostragens na safra "da seca". Catalão, GO, 2007.

\begin{tabular}{|c|c|c|c|c|c|c|}
\hline \multirow{2}{*}{ Genótipos $^{1,2}$} & \multicolumn{5}{|c|}{ Dias após a emergência das plantas } & \multirow{2}{*}{ Média } \\
\hline & 14 dias & 21 dias & 28 dias & 35 dias & 42 dias & \\
\hline 1- IAC-Tybatã & 17,3 & $88,0 \mathrm{ab}$ & $6,3 \mathrm{ab}$ & 22,7 & 8,7 & 28,60 \\
\hline 2- IAC-Una & 24,7 & $96,3 \mathrm{ab}$ & $16,3 \mathrm{ab}$ & 3,7 & 8,3 & 29,86 \\
\hline 3- FT-Nobre & 21,3 & $52,0 \mathrm{~b}$ & $8,0 \mathrm{ab}$ & 9,3 & 5,7 & 19,26 \\
\hline 4- Pérola & 63,0 & 194,7 bc & $3,3 \mathrm{~b}$ & 20,3 & 7,0 & 57,66 \\
\hline 5- LP 98-122 & 17,0 & 35,3 a & $5,7 \mathrm{ab}$ & 6,7 & 1,7 & 13,28 \\
\hline 6- LP 02-130 & 14,3 & $58,7 \mathrm{~b}$ & $1,7 \mathrm{~b}$ & 26,0 & 5,0 & 21,14 \\
\hline 7- LP 01-38 & 19,7 & $252,7 \mathrm{c}$ & $3,7 \mathrm{~b}$ & 26,7 & 7,0 & 61,96 \\
\hline 8- LP 99-79 & 38,7 & $81,3 \mathrm{ab}$ & $8,0 \mathrm{ab}$ & 32,0 & 2,7 & 32,54 \\
\hline 9- BRS-Pontal & 17,0 & $117,3 \mathrm{bc}$ & $4,7 \mathrm{ab}$ & 9,3 & 16,0 & 32,86 \\
\hline 10- BRS-Requinte & 46,3 & $126,7 \mathrm{bc}$ & $5,0 \mathrm{ab}$ & 13,3 & 21,0 & 42,46 \\
\hline 11- BRS-Triunfo & 30,7 & $147,7 \mathrm{bc}$ & $3,0 \mathrm{~b}$ & 18,7 & 3,7 & 40,76 \\
\hline 12- BRS-Grafite & 21,3 & $100,0 \mathrm{bc}$ & $3,3 \mathrm{~b}$ & 26,7 & 10,7 & 32,40 \\
\hline 13- CV-48 & 39,0 & $44,0 \mathrm{a}$ & $6,3 \mathrm{ab}$ & 5,7 & 2,3 & 19,86 \\
\hline 14- Z-28 & 22,0 & $184,0 \mathrm{bc}$ & $23,7 \mathrm{a}$ & 46,7 & 6,3 & 56,54 \\
\hline F (Tratamentos) & $0,84^{\mathrm{NS}}$ & $3,42^{* *}$ & $2,16^{*}$ & $1,90^{\mathrm{NS}}$ & $0,67^{\mathrm{NS}}$ & $1,87^{\mathrm{NS}}$ \\
\hline C.V. (\%) & 39,44 & 28,36 & 40,59 & 38,05 & 60,49 & 30,39 \\
\hline
\end{tabular}

${ }^{1}$ Médias seguidas da mesma letra na coluna, não diferem entre si pelo teste de Tukey a $5 \%$ de probabilidade.

${ }^{2}$ Para analise os dados foram transformados em $(x+0,50)^{1 / 2}$

Aos 28 (DAE) os genótipos LP 02-130, BRSTriunfo; Pérola, BRS-Grafite e LP 01-38 (1,7; 3,0; 3,3; 3,3 e 3,7 ninfas) respectivamente, apresentaram as menores infestações da praga, sugerindo que estes genótipos apresentam algum componente morfológico e/ou químico que causam resistência ao inseto (LARA, 1991). O genótipo Z-28 apresentou o maior número de ninfas da mosca-branca $(23,7)$ em média por dez folíolos.
Jesus (2007) avaliando o comportamento de genótipos de feijoeiro em condições de campo em Jaboticabal, SP, observou também que é nesse período que ocorre as maiores infestações da praga. BOIÇA JUNIOR; VENDRAMIM (1986) observaram que no genótipo BAT 363 houve reduzido número deninfas da praga e menor oviposição. Já as pesquisas deFARIA (1998), levou a recomendação do genótipo Ônix para o cultivo na época da seca para o Estado de Goiás. 
Tabela 3 - Número médio de ovos de Bemisia tabaci biótipo B em dez folíolos, obtidos em 14 genótipos de feijoeiro, em cinco amostragens na safra "das águas”. Ipameri, GO, 2007.

\begin{tabular}{|c|c|c|c|c|c|c|}
\hline \multirow{2}{*}{ Genótipos $^{1}$} & \multicolumn{5}{|c|}{ Dias após a emergência das plantas } & \multirow{2}{*}{ Média } \\
\hline & 14 dias & 21 dias & 28 dias & 35 dias & 42 dias & \\
\hline 1- IAC-Tybatã & 3,0 & 2,0 & 0,0 & 2,7 & 0,0 & 1,5 \\
\hline 2- IAC-Una & 2,7 & 0,0 & 0,0 & 0,0 & 0,0 & 0,5 \\
\hline 3- FT-Nobre & 8,0 & 4,7 & 0,3 & 0,0 & 0,0 & 2,6 \\
\hline 4- Pérola & 3,0 & 2,0 & 0,0 & 2,0 & 0,3 & 1,5 \\
\hline 5- LP 98-122 & 3,7 & 3,7 & 0,7 & 1,3 & 0,0 & 1,9 \\
\hline 6- LP 02-130 & 5,0 & 1,3 & 1,3 & 0,3 & 0,3 & 1,6 \\
\hline 7- LP 01-38 & 7,3 & 2,0 & 0,3 & 0,7 & 0,0 & 2,1 \\
\hline 8- LP 99-79 & 5,7 & 1,3 & 0,0 & 0,3 & 0,0 & 1,5 \\
\hline 9- BRS-Pontal & 8,7 & 1,0 & 0,3 & 0,3 & 0,3 & 2,1 \\
\hline 10- BRS-Requinte & 5,7 & 1,0 & 2,0 & 1,3 & 0,0 & 2,0 \\
\hline 11- BRS-Triunfo & 1,7 & 0,0 & 0,3 & 0,3 & 0,0 & 0,5 \\
\hline 12- BRS-Grafite & 2,7 & 0,0 & 0,0 & 0,0 & 0,0 & 0,5 \\
\hline 13- CV-48 & 3,3 & 3,0 & 2,0 & 0,3 & 0,0 & 1,7 \\
\hline 14- Z-28 & 4,0 & 1,3 & 0,3 & 0,3 & 0,7 & 1,3 \\
\hline F (Tratamentos) & $0,75^{\mathrm{NS}}$ & $1,24^{\mathrm{NS}}$ & $0,84^{\mathrm{NS}}$ & $1,97^{\mathrm{NS}}$ & $0,79^{\mathrm{NS}}$ & 1,12 \\
\hline C. V. $(\%)$ & 50,11 & 50,05 & 49,99 & 37,13 & 25,26 & 42,51 \\
\hline
\end{tabular}

${ }^{1}$ Para analise os dados foram transformados em $(x+0,50)^{1 / 2}$

Tabela 4- Número médio de ninfas de Bemisia tabaci biótipo B em dez folíolos, obtidos em 14 genótipos de feijoeiro, em cinco amostragens na safra "das águas". Ipameri, GO, 2007.

\begin{tabular}{|c|c|c|c|c|c|c|}
\hline \multirow{2}{*}{ Genótipos $^{1}$} & \multicolumn{5}{|c|}{ Dias após a emergência das plantas } & \multirow{2}{*}{ Média } \\
\hline & 14 dias & 21 dias & 28 dias & 35 dias & 42 dias & \\
\hline 1- IAC-Tybatã & 0,0 & 0,7 & 0,7 & 2,3 & 0,3 & 0,8 \\
\hline 2- IAC-Una & 5,3 & 8,7 & 0,7 & 1,3 & 0,3 & 3,3 \\
\hline 3- FT-Nobre & 5,7 & 2,7 & 0,7 & 1,0 & 0,0 & 2,0 \\
\hline 4- Pérola & 4,7 & 5,7 & 2,7 & 0,3 & 1,0 & 2,9 \\
\hline 5- LP 98-122 & 5,3 & 1,3 & 4,7 & 0,3 & 1,7 & 2,7 \\
\hline 6- LP 02-130 & 0,7 & 1,0 & 0,7 & 0,7 & 1,0 & 0,8 \\
\hline 7- LP 01-38 & 4,3 & 7,0 & 5,0 & 2,0 & 1,3 & 3,9 \\
\hline 8- LP 99-79 & 9,7 & 6,3 & 0,0 & 1,0 & 1,7 & 3,7 \\
\hline 9- BRS-Pontal & 7,3 & 1,3 & 2,7 & 1,3 & 0,3 & 2,6 \\
\hline 10- BRS-Requinte & 1,7 & 1,3 & 2,7 & 1,3 & 3,3 & 2,1 \\
\hline 11- BRS-Triunfo & 0,7 & 5,7 & 2,0 & 1,0 & 3,7 & 2,6 \\
\hline 12- BRS-Grafite & 0,0 & 2,3 & 0,0 & 0,0 & 0,7 & 0,6 \\
\hline 13- CV-48 & 6,7 & 7,0 & 1,3 & 1,0 & 1,3 & 3,5 \\
\hline 14- Z-28 & 2,7 & 6,3 & 0,0 & 0,3 & 0,3 & 1,9 \\
\hline F (Tratamentos) & $1,35^{\mathrm{NS}}$ & $1,43^{\mathrm{NS}}$ & $1,44^{\mathrm{NS}}$ & $0,68^{\mathrm{NS}}$ & $1,01^{\mathrm{NS}}$ & $1,18^{\mathrm{NS}}$ \\
\hline C. V. (\%) & 60,47 & 49,94 & 55,16 & 44,05 & 50,03 & 51,93 \\
\hline
\end{tabular}

Para analise os dados foram transformados em $(x+0,50)^{1 / 2}$

Nas demais avaliações não houve diferença estatística significativa entre os genótipos estudados.

Em relação à safra "das águas" os dados do número médio de ovos de mosca-branca por dez folíolos aos 14, 21, 28, 35 e 42 dias após emergência das plantas (DAE), encontram-se na Tabela 3.

Na safra "das águas" não houve diferença significativa entre os tratamentos, contudo na média ocorreu uma tendência de menor oviposição nos genótipos BRS-Grafite; BRS-Triunfo e IAC-Una (0,5; 0,5 e 0,5 ovos) e maior oviposição nos genótipos FT-Nobre, BRS-Pontal, BRS-Requinte, LP 01-38,
LP 98-122 e CV-48 (2,6; 2,1; 2,1; 2,0; 1,9 e 1,7 ovos) respectivamente.

Os dados do número médio de ninfas de mosca-branca na safra "das águas" por dez folíolos encontram-se na Tabela 4. Estatisticamente não houve diferença entre os tratamentos avaliados, porém ocorreu uma tendência de menor presença de ninfas nos genótipos BRS-Grafite; IAC-Tybatã e LP 02-130 com médias de (0,6; 0,8 e 0,8 ninfas) e maior número de ninfas de $B$. tabaci biótipo $B$, nos genótipos LP 01-38, LP 99-79 e CV-48 apresentando uma média de (3,9;3,7 e 3,5 ninfas) respectivamente. 
Tabela 5- Valores médios referente ao número de vagens, massa total de grãos, massa de 100 grãos e número de grãos por vagem, obtidos em 14 genótipos de feijoeiro na safra "da seca". Catalão, GO, 2007.

\begin{tabular}{|c|c|c|c|c|}
\hline \multirow[b]{2}{*}{ Genótipos $^{1,2}$} & \multicolumn{4}{|c|}{ Análise de 10 plantas de feijoeiro } \\
\hline & $\mathrm{N}^{\mathrm{o}}$ de vagens & $\begin{array}{c}\text { Massa total de } \\
\text { grãos (g) }\end{array}$ & $\begin{array}{c}\text { Massa de } 100 \\
\text { grãos (g) }\end{array}$ & $\begin{array}{c}\mathrm{N}^{\circ} \text { de grãos por } \\
\text { vagem }\end{array}$ \\
\hline 1- IAC-Tybatã & $164,33 \mathrm{ab}$ & 209,80 & $25,24 \mathrm{~b}$ & $4,87 \mathrm{ab}$ \\
\hline 2- IAC-Una & $206,00 \mathrm{ab}$ & 214,49 & $23,43 \mathrm{~b}$ & $4,53 \mathrm{~b}$ \\
\hline 3- FT-Nobre & $218,67 \mathrm{ab}$ & 230,16 & $19,58 \mathrm{~b}$ & $5,38 \mathrm{ab}$ \\
\hline 4- Pérola & $181,67 \mathrm{ab}$ & 221,73 & $24,16 \mathrm{~b}$ & $5,05 \mathrm{ab}$ \\
\hline 5- LP 98-122 & $204,33 \mathrm{ab}$ & 258,59 & $25,70 \mathrm{~b}$ & $5,24 \mathrm{ab}$ \\
\hline 6- LP 02-130 & $156,67 \mathrm{ab}$ & 174,73 & $24,06 \mathrm{~b}$ & $4,64 \mathrm{~b}$ \\
\hline 7- LP 01-38 & $139,33 \mathrm{~b}$ & 150,35 & $23,70 \mathrm{~b}$ & $4,35 \mathrm{~b}$ \\
\hline 8- LP 99-79 & $149,67 \mathrm{ab}$ & 168,18 & $22,41 \mathrm{~b}$ & $4,98 \mathrm{ab}$ \\
\hline 9- BRS-Pontal & $179,67 \mathrm{ab}$ & 269,25 & $23,70 \mathrm{~b}$ & $6,70 \mathrm{a}$ \\
\hline 10- BRS-Requinte & $156,00 \mathrm{ab}$ & 228,60 & $26,60 \mathrm{ab}$ & $5,51 \mathrm{ab}$ \\
\hline 11- BRS-Triunfo & $178,00 \mathrm{ab}$ & 192,48 & $19,60 \mathrm{~b}$ & $5,54 \mathrm{ab}$ \\
\hline 12- BRS-Grafite & $189,33 \mathrm{ab}$ & 263,31 & $40,40 \mathrm{a}$ & $4,06 \mathrm{~b}$ \\
\hline 13- CV-48 & $172,00 \mathrm{ab}$ & 242,29 & $27,45 \mathrm{ab}$ & $5,27 \mathrm{ab}$ \\
\hline 14- Z-28 & $229,33 \mathrm{a}$ & 234,12 & $22,62 \mathrm{~b}$ & $4,45 \mathrm{~b}$ \\
\hline F (tratamentos) & $1,19^{* *}$ & $1,11^{\mathrm{NS}}$ & $1,36^{* *}$ & $1,65^{* *}$ \\
\hline C. V. $(\%)$ & 11,68 & 14,36 & 12,35 & 7,84 \\
\hline
\end{tabular}

${ }^{1}$ Médias seguidas pela mesma letra na coluna não diferem estatisticamente pelo teste Tukey $5 \%$.

${ }^{2}$ Para analise os dados foram transformados em $(\mathrm{x}+0,50)^{1 / 2}$

Tabela 6- Valores médios referente ao número de plantas por $4 \mathrm{~m}^{2}$, rendimento em gramas por $4 \mathrm{~m}^{2}$ e $\mathrm{Mg}^{-1}$ habtidos em 14 genótipos de feijoeiro na safra “da seca". Catalão, GO, 2007.

\begin{tabular}{|c|c|c|c|}
\hline \multirow{2}{*}{ Genótipos ${ }^{1,2}$} & \multirow{2}{*}{$\mathrm{N}^{\mathrm{o}}$ de plantas $/\left(4 \mathrm{~m}^{2}\right)$} & \multicolumn{2}{|c|}{ Rendimento } \\
\hline & & $\mathrm{g} /\left(4 \mathrm{~m}^{2}\right)$ & $\mathrm{Mg} / \mathrm{ha}^{-1}$ \\
\hline 1- IAC-Tybatã & $64,00 \mathrm{a}$ & 647,92 & 1,62 \\
\hline 2- IAC-una & $52,00 \mathrm{abc}$ & 885,41 & 2,22 \\
\hline 3- FT-Nobre & $48,67 \mathrm{abc}$ & 758,60 & 1,90 \\
\hline 4- Pérola & $62,67 \mathrm{a}$ & 798,94 & 2,00 \\
\hline 5- LP 98-122 & $36,33 \mathrm{c}$ & 581,27 & 1,45 \\
\hline 6- LP 02-130 & $46,67 \mathrm{abc}$ & 605,02 & 1,51 \\
\hline 7- LP 01-38 & $54,00 \mathrm{abc}$ & 683,25 & 1,71 \\
\hline 8- LP 99-79 & $58,00 \mathrm{ab}$ & 645,22 & 1,61 \\
\hline 9- BRS-Pontal & $40,33 \mathrm{bc}$ & 686,39 & 1,72 \\
\hline 10- BRS-Requinte & $61,33 \mathrm{a}$ & 671,63 & 1,68 \\
\hline 11- BRS-Triunfo & $60,00 \mathrm{a}$ & 922,19 & 2,31 \\
\hline 12- BRS-Grafite & $47,33 \mathrm{abc}$ & 778,87 & 1,95 \\
\hline 13- CV-48 & $44,33 \mathrm{abc}$ & 587,26 & 1,47 \\
\hline 14- Z-28 & $54,33 \mathrm{abc}$ & 812,02 & 2,03 \\
\hline F (tratamentos) & $2,28^{* *}$ & $0,68^{\mathrm{NS}}$ & $0,69^{\mathrm{NS}}$ \\
\hline C. V. $(\%)$ & 9,51 & 16,62 & 12,63 \\
\hline
\end{tabular}

${ }^{1}$ Médias seguidas pela mesma letra na coluna não diferem estatisticamente pelo teste Tukey $5 \%$.

${ }^{2}$ Para analise os dados foram transformados em $(x+0,50)^{1 / 2}$

BOIÇA JUNIOR et al. (2008), avaliando a interação de genótipos de feijoeiro e inseticidas naturais e químicos no controle de B. tabaci biótipo B em diferentes épocas de cultivos, observaram menores infestações e oviposições da praga nas safras "das água" e "de inverno" em relação à "safra da seca". O mesmo foi constatado por JESUS (2007), avaliando a resistência de genótipos de feijoeiro nas três épocas de cultivo.
Na Tabela 5, encontram-se os dados médios referente ao número médio de vagens por dez plantas, massa total média de grãos em dez plantas, massa média de 100 grãos e o número médio de grãos por vagem. Analisando os valores obtidos, o genótipo que apresentou maior número de vagens foi Z-28 $(229,33)$ e menor LP 01-38 $(139,33)$. O valor da massa total média de grãos em dez plantas, não 
Tabela 7- Valores médios referente ao número de vagens, massa total de grãos, massa de 100 grãos e número de grãos por vagem, obtidos em 14 genótipos de feijoeiro na safra "das águas". Ipameri, GO, 2007.

\begin{tabular}{|c|c|c|c|c|}
\hline \multirow{2}{*}{ Genótipos $^{1}$} & \multicolumn{4}{|c|}{ Análise de 10 plantas de feijoeiro } \\
\hline & $\mathrm{N}^{\mathrm{o}}$ de vagens & Massa total de grãos (g) & Massa de 100 grãos (g) & $\mathrm{N}^{\mathrm{o}}$ de grãos por vagem \\
\hline 1- IAC-Tybatã & 144,61 & 184,62 & 22,21 & 4,29 \\
\hline 2- IAC-Una & 147,28 & 188,75 & 20,62 & 3,99 \\
\hline 3- FT-Nobre & 210,02 & 202,54 & 17,23 & 4,73 \\
\hline 4- Pérola & 159,87 & 195,12 & 21,26 & 4,44 \\
\hline 5- LP 98-122 & 179,81 & 227,56 & 22,62 & 4,61 \\
\hline 6- LP 02-130 & 137,87 & 153,76 & 21,17 & 4,08 \\
\hline 7- LP 01-38 & 142,50 & 132,31 & 20,86 & 3,83 \\
\hline 8- LP 9979 & 131,71 & 148,00 & 19,72 & 4,38 \\
\hline 9- BRS-Pontal & 138,24 & 236,94 & 20,86 & 4,34 \\
\hline 10- BRS-Requinte & 137,28 & 201,17 & 23,41 & 4,85 \\
\hline 11- BRS-Triunfo & 156,64 & 169,38 & 17,25 & 4,88 \\
\hline 12- BRS-Grafite & 152,58 & 231,71 & 21,12 & 3,57 \\
\hline 13- CV-48 & 145,36 & 213,22 & 23,24 & 4,64 \\
\hline 14- Z-28 & 201,81 & 206,03 & 19,91 & 3,92 \\
\hline F (tratamentos) & $1^{\mathrm{NS}}$ & $1^{\mathrm{NS}}$ & $1^{\mathrm{NS}}$ & $1^{\mathrm{NS}}$ \\
\hline C. V. (\%) & 12,20 & 13,95 & 6,7 & 5,64 \\
\hline
\end{tabular}

${ }^{1}$ Para analise os dados foram transformados em $(x+0,50)^{1 / 2}$

Tabela 8 - Valores médios referente ao número de plantas por $4 \mathrm{~m}^{2}$, rendimento em gramas por $4 \mathrm{~m}^{2}$ e $\mathrm{Mg} \mathrm{ha}^{-1}$, obtidos em 14 genótipos de feijoeiro na safra “das águas”. Ipameri, GO, 2007.

\begin{tabular}{|c|c|c|c|}
\hline \multirow{2}{*}{ Genótipos $^{1}$} & \multirow{2}{*}{$\mathrm{N}^{\mathrm{o}}$ de plantas $/\left(4 \mathrm{~m}^{2}\right)$} & \multicolumn{2}{|c|}{ Rendimento } \\
\hline & & $\mathrm{g} /\left(4 \mathrm{~m}^{2}\right)$ & $\mathrm{Mg} / \mathrm{ha}^{-1}$ \\
\hline 1- IAC-Tybatã & 56,00 & 570,17 & 1,43 \\
\hline 2- IAC-una & 59,00 & 779,16 & 1,95 \\
\hline 3- FT-Nobre & 45,20 & 667,57 & 1,67 \\
\hline 4- Pérola & 54,17 & 703,07 & 1,76 \\
\hline 5- LP 98-122 & 42,15 & 511,52 & 1,28 \\
\hline 6- LP 02-130 & 56,20 & 532,42 & 1,33 \\
\hline 7- LP 01-38 & 57,00 & 601,26 & 1,50 \\
\hline 8- LP 9979 & 63,28 & 567,79 & 1,42 \\
\hline 9- BRS-Pontal & 46,41 & 604,02 & 1,51 \\
\hline 10- BRS-Requinte & 65,24 & 591,03 & 1,48 \\
\hline 11- BRS-Triunfo & 58,74 & 811,53 & 2,03 \\
\hline 12- BRS-Grafite & 51,02 & 685,41 & 1,72 \\
\hline 13- CV-48 & 56,78 & 516,79 & 1,29 \\
\hline 14- Z-28 & 45,13 & 714,58 & 1,79 \\
\hline F (tratamentos) & $1^{\mathrm{NS}}$ & $1^{\mathrm{NS}}$ & $1^{\mathrm{NS}}$ \\
\hline C. V. $(\%)$ & 10,30 & 12,57 & 7,31 \\
\hline
\end{tabular}

${ }^{1}$ Para analise os dados foram transformados em $(x+0,50)^{1 / 2}$

apresentou diferença estatística entre os tratamentos. Para a massa média em gramas de 100 grãos o maior valor foi visualizado em BRS-Grafite $(40,40)$, BRS-Requinte $(26,60)$ e CV-48 $(27,45)$ e o menor em FT-Nobre $(19,58)$, porém sem diferir dos demais. Em relação ao número médio de grãos por vagem o maior valor foi observado em BRS-Pontal $(6,7)$ e o menor em BRS-Grafite (4,06), LP 01-38 (4,35), Z-28 $(4,45)$, IAC Una $(4,53)$ e LP 02-120 $(4,64)$.

Na Tabela 6, encontram-se os dados referentes ao número médio de plantas por $4 \mathrm{~m}^{2}$ (área útil do tratamento), rendimento médio em gramas por 4 $\mathrm{m}^{2}$ e produção média em megagramas por hectare, mostrando que houve diferença significativa somente no número médio de plantas por $4 \mathrm{~m}^{2}$.

Para a avaliação do número médio de plantas, o maior valor foi observado em IAC-Tybatã $(64,00)$, Perola $(62,67)$, BRS-Requinte $(61,33)$ e BRS-Triunfo $(60,00)$ e o menor em LP- $98-122(36,33)$. Uma observação relevante é que mesmo com o estande final de plantas variando, os tratamentos não apresentaram diferença estatística entre si no rendimento de grãos. 
Em relação à safra "das águas" não houve diferença estatística entre nenhum parâmetro avaliado em relação aos dados de produção (Tabelas 7 e 8).

Não foram observados sintomas do vírus do mosaico-dourado do feijoeiro em nenhuma das avaliações realizadas em ambas as safras.

\section{CONCLUSÕES}

Nas condições do presente experimento concluise que:

- Os genótipos IAC-Una, LP 02-130 foram menos ovipositados pela B. tabaci biótipo B na safra "da seca"; - Os genótipos LP 98-122 e FT-Nobre apresentaram as menores infestações de ninfas de mosca-branca na safra "da seca";

- As maiores oviposições ocorreram aos 14 DAE e maiores infestações de ninfas de $B$. tabaci biótipo B aos 21 DAE na safra "da seca";

- As maiores infestações de B. tabaci biótipo B ocorreram na safra "da seca".

\section{REFERÊNCIAS}

BARBOSA FILHO, M. P.; FAGERIA, N. K.; SILVA, O. F. Aplicação de Nitrogênio em Cobertura no Feijoeiro Irrigado. Santo Antônio de Goiás: Embrapa-CNPAF, 2001. 8p. (Circular Técnica, 49).

BOIÇA JUNIOR, A.L.; VENDRAMIM, J.D.; Desenvolvimento de Bemisia tabaci em genótipos de feijão. Anais da Sociedade Entomológica do Brasil, v.15, p.231-238, 1986.

BOIÇA JUNIOR, A.L.; JESUS, F.G.; CARBONELL, S.A.M.; PITTA, R.M.; CHIORATTO, A.F. Efeito de genótipos de Phaseolus vulgaris associado ou não a inseticidas no controle de Bemisia tabaci biótipo B (Hemiptera: Aleyrodidae) e Caliothrips phaseoli (Thysanoptera:Thripidae). Boletín de Sanidad Vegetal. Plagas, v.34, p.22-27, 2008.

FARIA, J.C.; ANJOS, J.R.N.; COSTA, A.F.; SPERÂNDIO, C.A.; COSTA, C.L. Doenças causadas por vírus e seu controle. In: ARAUJO, R.S.; RAVA, C.A.; STONE DROST, Y.C.; VAN LENTEREN, J.C.; VAN ROERMUND, H.J.W. (Ed.). Life history parameters of different biotypes of Bemisia tabaci (Hemiptera: Aleyrodidae) in relation to temperature and host plant: a selective review. Wallingford: Cambridge University, 1998. Bulletin Entomological Research, v.88, p.219-229, 1998.
JESUS, F.G. Resistência de genótipos de feijoeiro ao ataque de Bemisia tabaci biótipo B (Hemiptera: Aleyrodidade) $e$ Caliothrips phaseoli (Thysanoptera: Tripidae). 2007. 83f. Dissertação (Mestrado) - Faculdade de Ciências Agrárias e Veterinárias, Universidade Estadual Paulista, Jaboticabal, 2007.

LARA, F.M. Princípios da resistência de plantas a insetos. São Paulo: Ícone, 1991. 336p.

MAGALHÃES, B.P.; CARVALHO, S.M. Insetos associados à cultura. Cultura do feijoeiro: fatores que afetam a produtividade. Piracicaba: FEALQ, 1998. 573p.

McAUSLANE, H.J. Influence of leaf pubescence on ovipositional preference of Bemisia argentifolii (Homoptera: Aleyrodidae) on soybean. Environmental Entomology, v.25, p.834-841, 1996

ORIANI, M.A.G.; VENDRAMIM, J.D.; BRUNHEROTTO, R. Atratividade e não-preferência para oviposição de Bemisia tabaci (Genn.) biótipo B (Hemiptera: Aleyrodidae) em genótipos de feijoeiro. Neotropical Entomology, v.34, p.105-111, 2005.

PRABHAKER, N.; COUDRIET, D.L.; MEYERDIRK, D.E. Insecticide resistance in the sweetpotato whitefly, Bemisia tabaci (Homoptera: Aleyrodidae). Journal of Economic Entomology, v.78, p.748-752. 1985.

ROSSETTO, D.; COSTA, A.S.; MIRANDA, M.A.C.; NAGAI, V.; ABRAMIDES, E. Diferenças na oviposição de Bemisia tabaci em variedades de soja. Anais da Sociedade Entomologica do Brasil, v.6, p.256-263, 1977.

SILVA, A.L.; VELOSO, V.R.S.; NASCIMENTO, I.M.; OLIVEIRA, J.P.; PALHARES, D.M. Avaliação do befenthrin no controle da mosca branca (Bemisia tabaci) em feijoeiro. Anais da Escola de Agronomia e Veterinária, v.23, p.1-6, 1993.

VIEIRA, C.; PAULA JÚNIOR, T.J.; BORÉM, A. Feijão. 2.ed. Viçosa: Editora-Viçosa, 2006. p.14-15.

VIEIRA, C.; PAULA JÚNIOR, T.J.; BORÉM, A. Feijão: aspectos gerais e cultura no Estado de Minas. Viçosa: UFV, 1998. 596p.

Recebido em 5/6/09

Aceito em 15/11/09 